\title{
Numerical modelling of the hydrodynamic behaviour of the couple piston-liner
}

\author{
A. Soualmia*, M. Bouchetara** \\ *University of Sciences and the Technology of Oran, L.P 1505 El-Menaouer, USTO 31000 Oran, Algeria, \\ E-mail: soualmia.aek@hotmail.fr \\ **University of Sciences and the Technology of Oran, L.P 1505 El-Menaouer, USTO 31000 Oran, Algeria, \\ E-mail: mbouchetara@hotmail.com
}

cross $^{\text {ref }}$ http://dx.doi.org/10.5755/j01.mech.21.6.7035

\section{Nomenclature}

$w$ - net resultant radial force, $\mathrm{N} ; a$ - width of parabolic portion of the ring face, $\mathrm{mm} ; b$ - width of the straight portion of the ring face, $\mathrm{mm} ; \delta$ (delta) - the inclination of the wedge, degree; $c$-minimum film thickness, $\mathrm{mm} ; h$-oil film thickness which is the function of $x, \mathrm{~mm} ; x$ - the coordinate distance reckoned from the leading edge of the ring, $\mathrm{mm} ; N$-number of iterations; $P$-hydrodynamic pressure, $\mathrm{Pa}$; $U$ - piston velocity in axial direction, $\mathrm{m} / \mathrm{s}$; $t$ - time, $\mathrm{s} ; X$ - Piston displacement, $\mathrm{m} ; R$ - ring radius, $\mathrm{m}$; $\theta$ - crank angle, degree; $L$ - stroke length, $\mathrm{m} ; \omega$ - the angular speed of the crank, rad/s; $\mu$ - viscosity of the oil, cst; $\tau$ - shear rate, $\mathrm{N} ; P_{u}$ - power dissipated, w; $F$ - friction force, $\mathrm{N} ; f$ - friction coefficient.

\section{Introduction}

The piston top compression ring plays a vital role in an efficient engine operation as it prevents the combustion gas leakage and allows heat dissipation, but contributes towards mechanical friction. Under severe operating conditions, the ring-block interface contributes about $20 \%$ of the total engine mechanical frictional loss [1-2]. Hence, the piston rings are lubricated by oil, the film thickness of which results in low friction and reduced wear. Major factors affecting the oil film thickness are bore distortion, piston speed, lubricant viscosity, top ring face profile, ring flexibility and boundary conditions.

The Parabolic face profile has the advantage that it tends to be self perpetuating under wear since ring tends to rock inside its groove during reciprocating movement and causes preferential wear of its edges [3]. This model generates hydrodynamic pressure fields and minimum hydrodynamic film thickness profiles as functions of engine crankshaft rotation of 720 degree, apart from calculating the friction coefficient. Influence of load on the tribological condition in piston ring and cylinder liner contacts in a medium-speed diesel engine [4]. The experimental method for measuring the oil-film thickness between the piston-ring and cylinder-wall of internal combustion engines and compressor friction influence the minimum film theckness [5-6]. Piston Ring-Cylinder Bore Friction Modelling in Mixed Lubrication Regime influence the friction force and hydrodynamic pressure [7-8-10]. Our objective is to compute the evolution of the function $c(i)$ from an initial state. Hydrostatic pressure variations in the $y$ direction are assumed to be negligibly small. Reynolds equation which is to be solved subject to the specified and possibly time-dependent.

\section{Reynolds equation}

When hydrodynamic or mixed lubrication occurs, an averaged flow-factor Reynolds analysis is used to model the lubricant pressure and flows, and the interaction between the lubricant and surface asperities. Hydrodynamic support of the ring load depends on a "wedge" effect in which relative motion between sliding surfaces and changing flow area combine to increase pressure in the lubricant. The fluid pressure is then able to support an external load.

Because of this effect, a positive pressure increase will occur in the oil in the converging section of the ring/liner interface, and pressure will decrease in the diverging section.

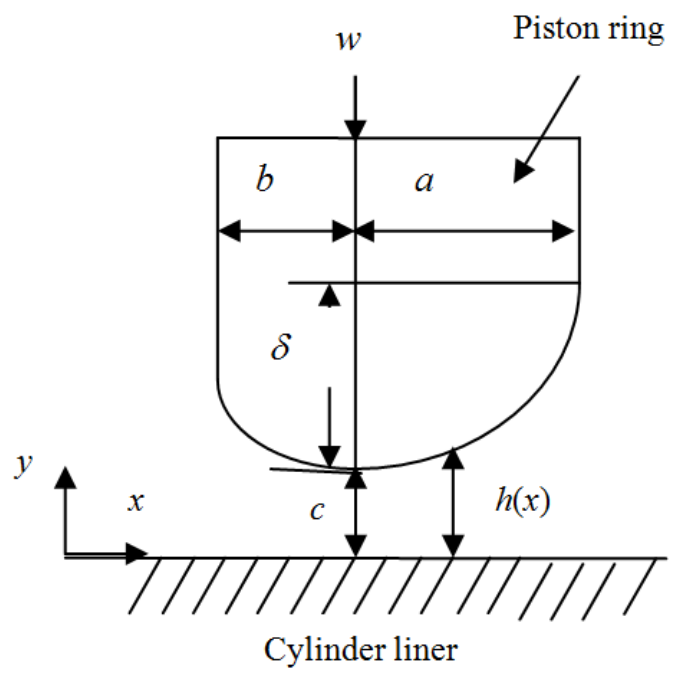

Fig. 1 Surface shape of the compression ring

Analysis of the lubricant pressure and flow between ring and liner is based on Reynolds' equation , which is applicable for thin film flows where viscous phenomena dominate fluid inertia. The Reynolds relationship is derived from conservation of momentum for the fluid and conservation of fluid mass (Continuity), and (for a one-dimensional system) is given by [11]:

$$
\frac{\partial}{\partial x}\left(\frac{h^{2}}{m} \frac{\partial P}{\partial x}\right)=-6 U \frac{\partial h}{\partial x}+12 \frac{d c}{d t} .
$$




\section{Numerical solution procedure}

The instantaneous velocity $U$ and displacement of the piston $X$ may be described by quasi-harmonic function of the angular position $\theta$ of the crankshaft in relation to the angular speed $\omega$, in accordance with the expressions [1]:

$$
\begin{aligned}
& X=L+R-\left[R \cos \theta+\sqrt{L^{2}-R^{2} \sin ^{2} \theta}\right] ; \\
& U=\frac{R}{b} \sin \theta\left[1-\frac{\cos \theta}{\sqrt{\left(\frac{L}{b}\right)^{2}-(\sin \theta)^{2}}}\right] b \omega ;
\end{aligned}
$$

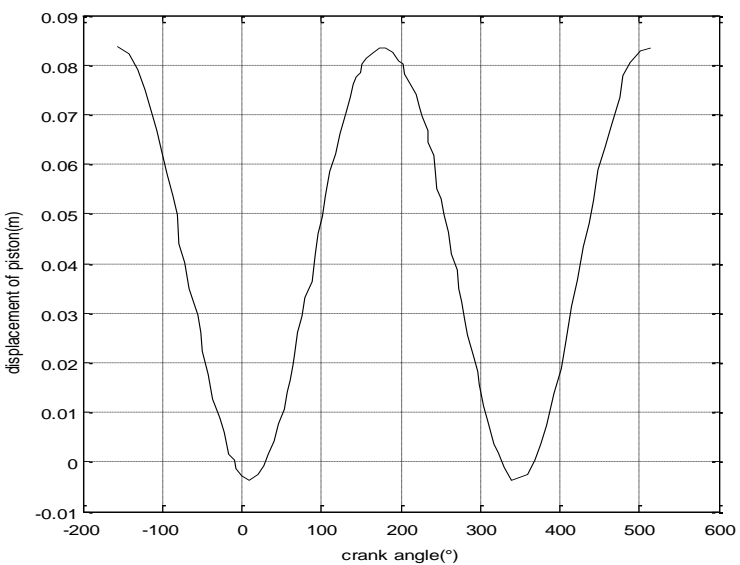

Fig. 2 Piston displacement $V s$ crank angle

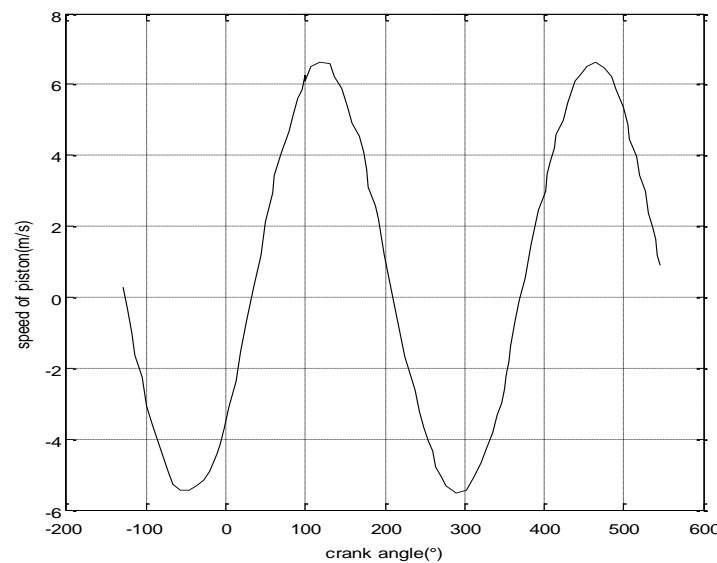

Fig. 3 Piston speed $V s$ crank angle

\section{The forces acting on the ring}

Piston rings are metallic gaskets whose functions are to seal the combustion chamber against the crankcase, to transmit heat from the piston to the cylinder wall, and to regulate the amount of oil present on the cylinder sleeve, a function of the oil control ring in particular. It is necessary for this purpose that the piston rings be in close contact with both the cylinder wall and the flank of the groove machined into the piston. Contact with the cylinder wall is ensured by the spring action inherent to the ring itself, which expands the ring radially.

There is considerable evidence which defines ring motion in the groove. The ring can tilt or move axially up and down in the groove. Here only the axial motion of the ring in the groove will be considered and assume that groove surfaces are flat. The forces acting on the ring in axial direction are shown in Fig. 4 and are following [3].

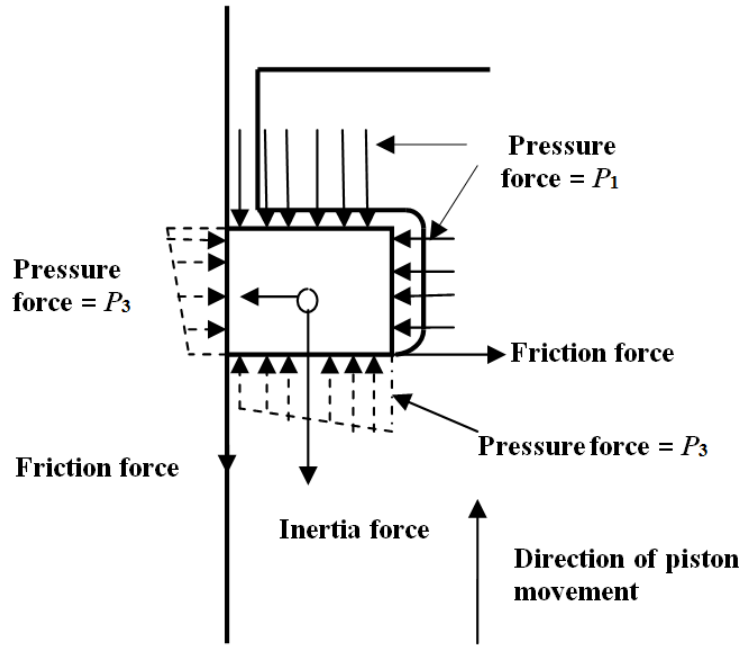

Fig. 4 Schematics showing various forces acting on the rings

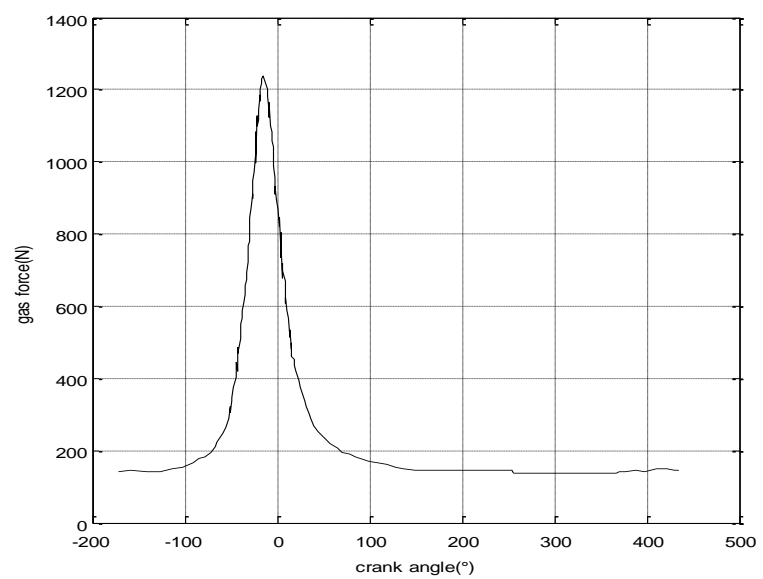

Fig. 5 Gas force $V s$ crank angle

The pressure force acting on the ring is given by:

$$
F_{p}=A_{r} \frac{P_{1}-P_{3}}{2}
$$

$A_{r}$ is the ring area in the radial direction; $P_{i}$ is the pressure in the regions, $i=1,2,3$.

The friction forces is calculated from the relation:

$$
F_{f}=p\left(\pi d_{r} T_{r}\right) f,
$$

$p$ - is the pressure behind the ring; $d_{r}$ is the diameter of the ring; $T_{r}$ is the thickness of the ring.

$$
f=4.8\left(\frac{\mu U}{p T_{r}}\right),
$$

$U$ is piston speed.

The inertia forces is due to the mass of the ring and calculated from the relation:

$$
F_{i}=M_{r} a_{p},
$$


$M_{r}$ is the mass of the ring; $a_{p}$ is the piston acceleration.

The Fig. 5 shows the variation in the force of combustion gas during an engine cycle. The force is maximum in the gas explosion is reached the actual value $1.2 \mathrm{KN}$.

\section{Problem identification}

Calculation and analysis of oil film thickness, Gas flows and effect of Hydrodynamic oil film on friction by using hydrodynamic model and taking Ring motion into account. The following assumptions are also taken into account in the formulation.

The ring geometric is full parabolic profile the Corner and squeeze terms are neglected in the equation of Reynold. The Reynolds boundary condition is used to the Reynold's equation.

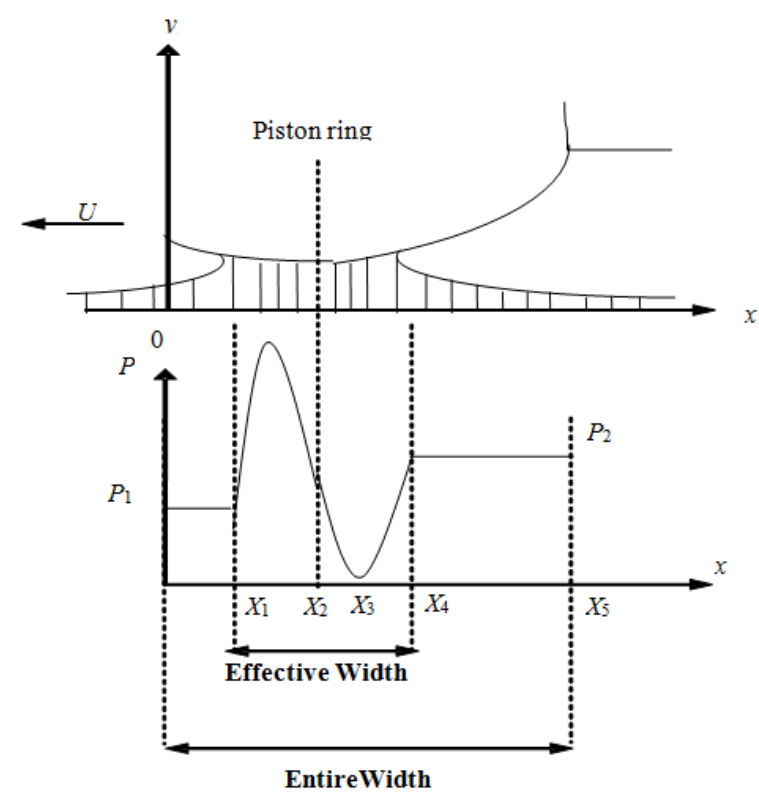

Fig. 6 Open-end boundary condition

Reynolds equation which is to be solved subject to the specified, and possibly time-dependent, boundary conditions $P(x=-b)=P_{1}(t)$ and $P(x=a)=P_{2}(t)$ show in the Fig. 6 . The vertical velocity of the body $V_{B}=d c / d t$ is determined by the balance between the liner of the ring, denoted by $W$, and the lifting force due to the pressure, expressed by [13]:

$$
w=\int_{-b}^{a} P(x, t) d x
$$

The solution may be computed using the following algorithm with Fortran program is illustrated in Fig 7 : Eq. (1):

1) Solve the following simplified version of

$$
\frac{\partial}{\partial x}\left(\frac{h^{3}}{\mu} \frac{\partial P}{\partial x}\right)=6 U \frac{\partial h}{\partial x}
$$

subject to the required boundary conditions $P(x=-b)=P_{1}(t)$ and $P(x=a)=P_{2}(t)$, et and call the solution $P_{1}(x)$;
2) Solve the following simplified version of Eq. (1):

$$
\frac{\partial}{\partial x}\left(\frac{h^{3}}{\mu} \frac{\partial P}{\partial x}\right)=12
$$

subject to the homogeneous boundary conditions $P(x=-b)=0$ and $P(x=a)=0$, and call the solution $P_{2}(x)$

3) By the superposition principle:

$$
\frac{\partial}{\partial x}\left(\frac{h^{3}}{\mu} \frac{\partial P}{\partial x}\right)=P_{1}(x)+\frac{d c}{d t} P_{2}(x) ;
$$

4) Substitute the pressure distribution (10) into the force balance (8) and carry out the integration to compute $d c / d t$.

5) Having evaluated $d c / d t$, update the minimum clearance $c$.

6) Solve of shear rate expressed by:

$$
\tau(x)=-\mu \frac{U}{h(x)}+\frac{h(x)}{2} \frac{d P}{d x} ;
$$

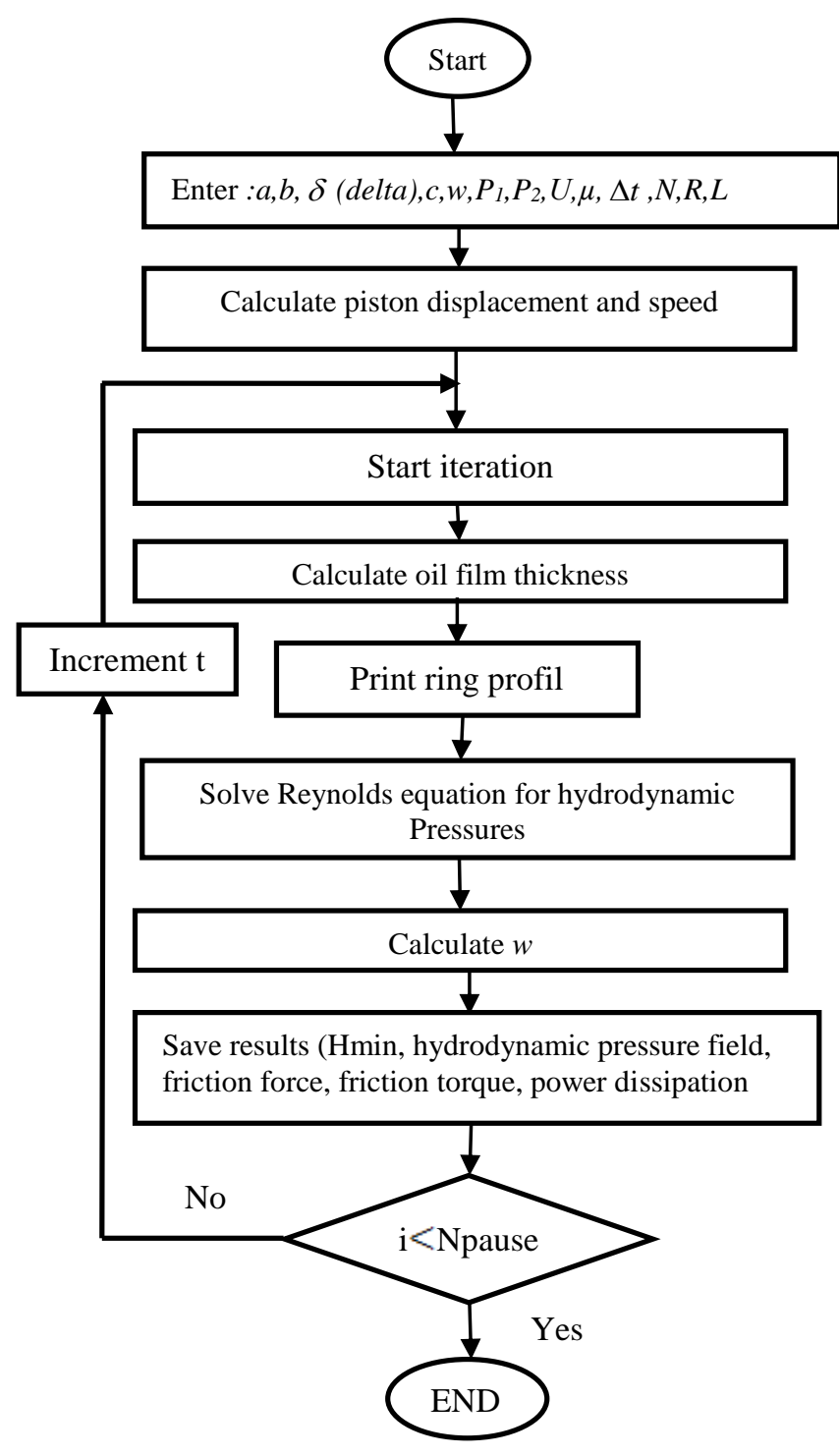

Fig. 7 Flowchart of computational scheme 
7) The friction force is obtained by integration of the shear rate:

$$
F=\int_{-b}^{a} \tau(x) d x ;
$$

8) The power dissipated by shear is:

$$
P_{u}=F U
$$

and the friction coefficient is:

$$
F_{f}=p\left(\pi d_{r} T_{r}\right) f ;
$$

9) Return to step 1 and repeat.

\section{Numerical results and discussion}

\subsection{Effect of ring profile}

Fig. 8 illustrates the hydrodynamic pressure between the ring and the cylinder. this pressure is maximum at the point $\mathrm{C}$ due to the influence of the profile of the ring and of the combustion gases on the oil film; the parameter delta influence directly to the hydrodynamic pressure for delta $=0.25$ the maximum hydrodynamic pressure attain $2500 \mathrm{~Pa}$.

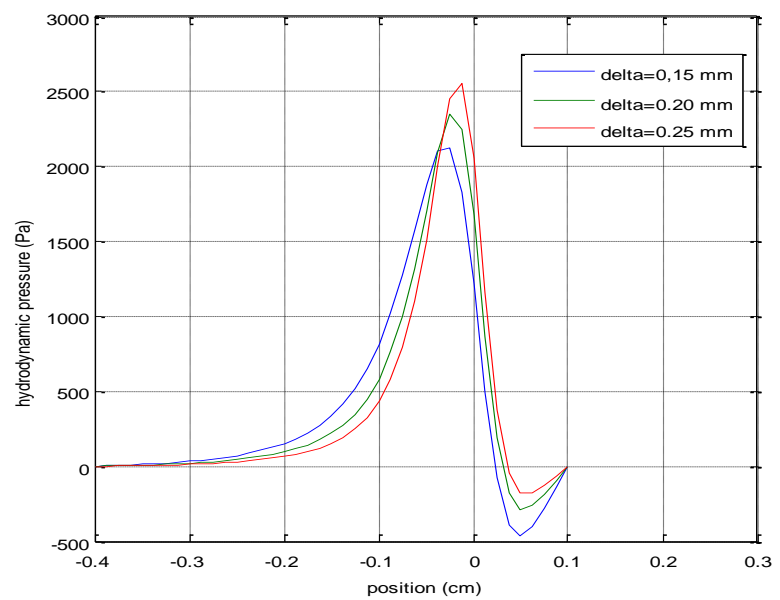

Fig. 8 Comparison of the results of the hydrodynamic pressure with different ring profiles

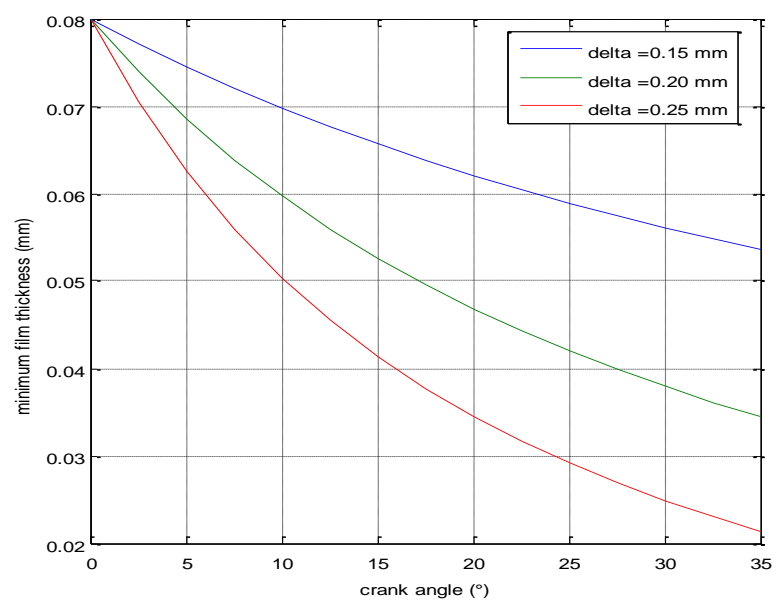

Fig. 9 Minimum film thickness $V s$ crank
Figs. 9 and 10 represents the variation of the minimum film thickness and the force of friction. The force of friction is inversely proportional to the inclination of the profile parameter delta and the minimum thickness to crank angle.

The Figs. 11 and 12 represents the variation of the dissipated power and the friction coefficient

The two parameters are proportional inversely proportional to the parameter delta.

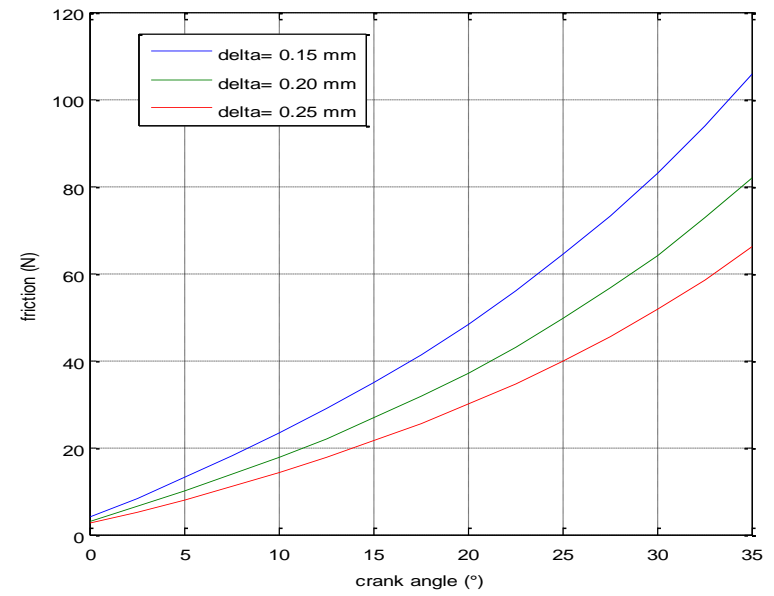

Fig. 10 Friction force $V s$ crank angle

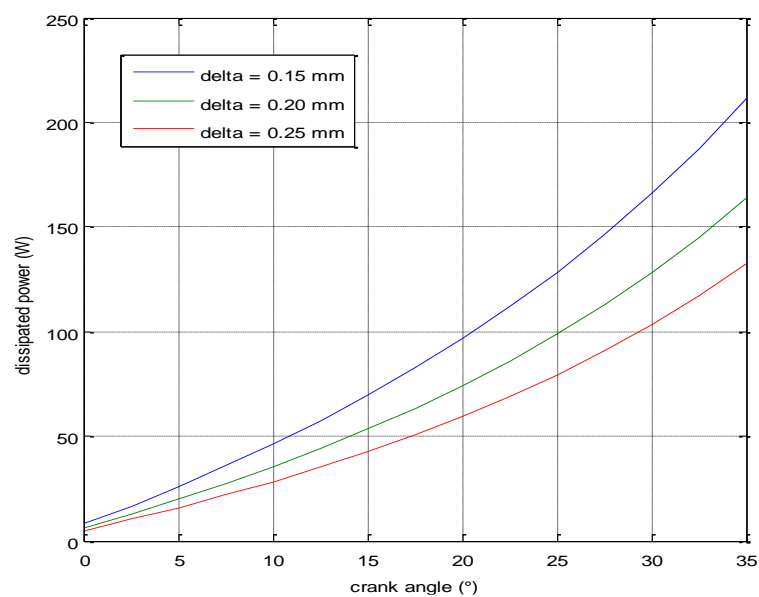

Fig. 11 Dissipated power $V s$ crank angle

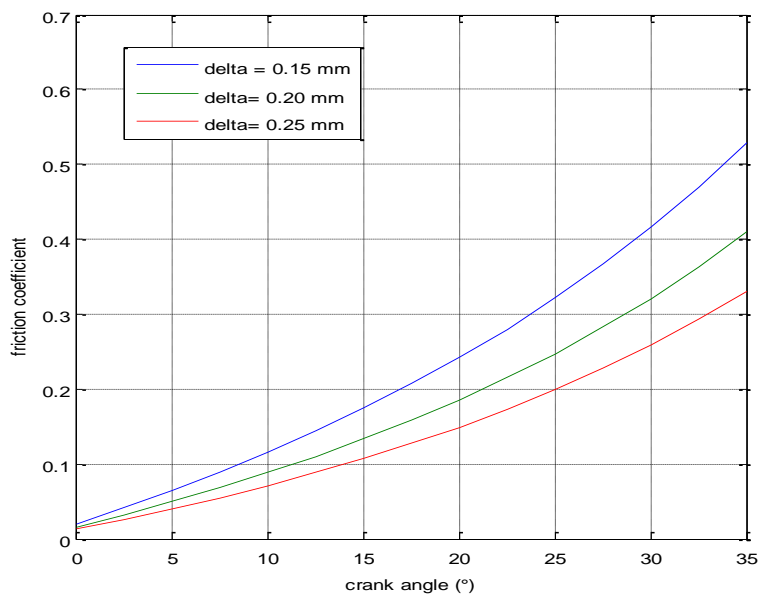

Fig. 12 Friction coefficient $V s$ crank angle

6.2. Effect of oil viscosity for $\delta$ (delta) $=025, W=100 \mathrm{~N}$

Fig. 13 show the hydrodynamic pressure between 
the cylinder and the ring. This pressure is maximum at the point $\mathrm{C}$ due to the influence of the profile of the ring and of the combustion gases on the oil film; the hydrodynamic pressure is proportional to the viscosity of the oil film.

Figs. 14 and 15represents the variation of the minimum film thickness of the oil film and the force of friction, the force of friction is inversely proportional to the viscosity of the oil film and the minimum film thickness to the crank angle.Figs. 16 and 17 represent the variation of the dissipated power and the friction coefficient proportional to the two parameters crank angle and inversely proportional to the viscosity of the oil film.

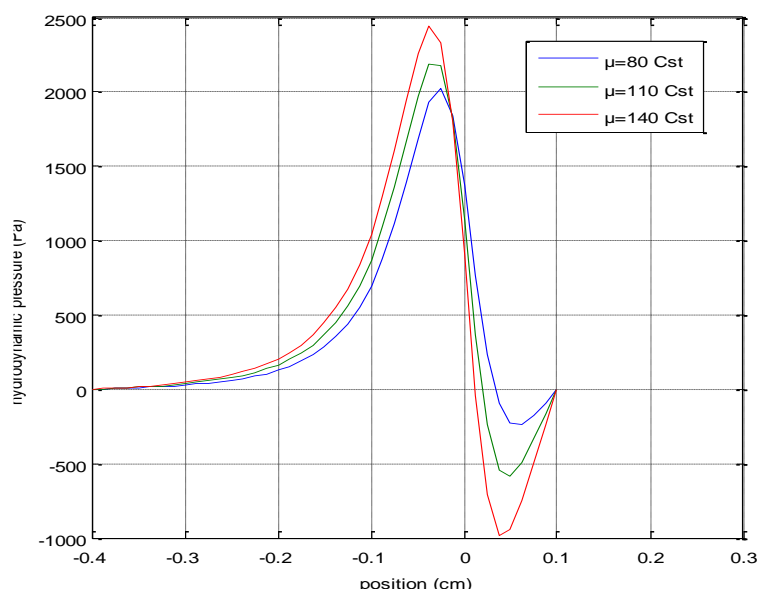

Fig. 13 The hydrodynamic pressure with different oil viscosity

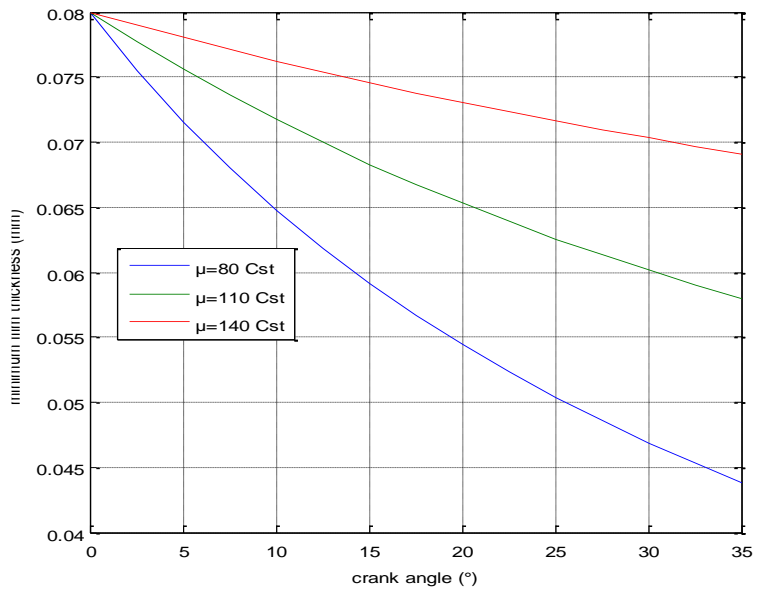

Fig. 14 Minimum film thickness $V s$ crank angle

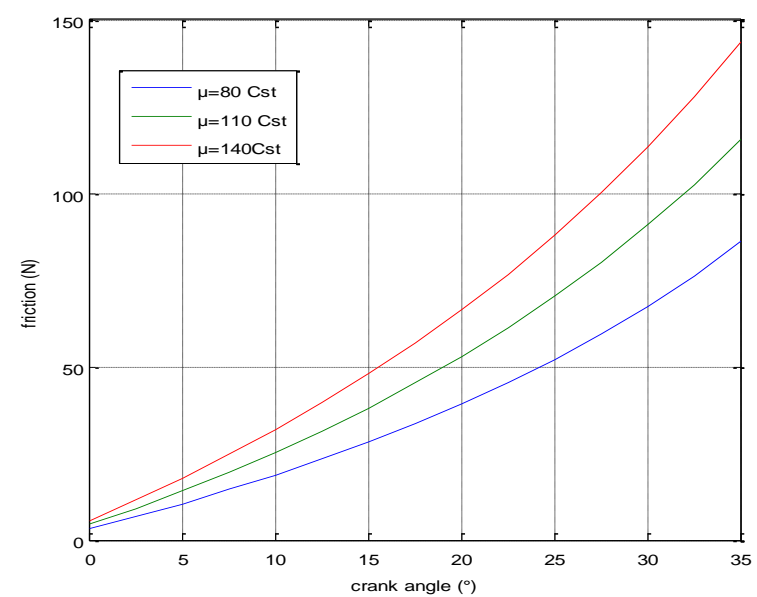

Fig. 15 Friction force $V s$ crank angle

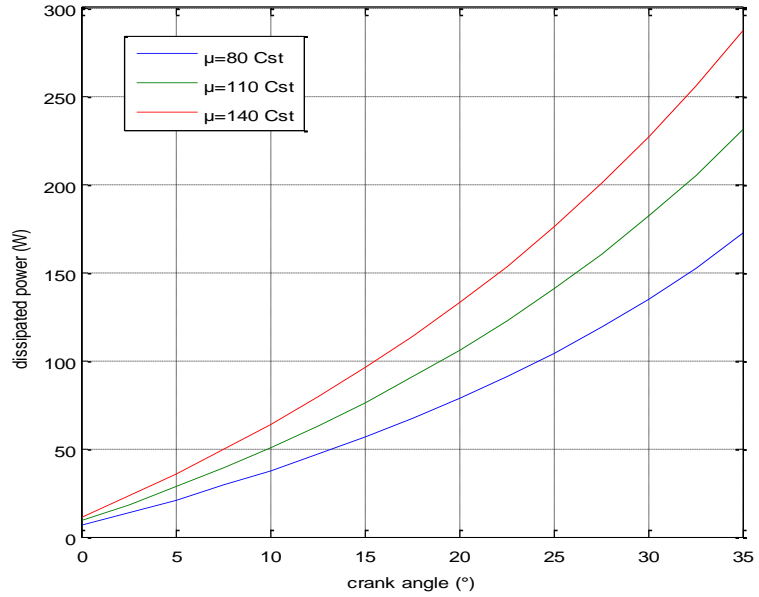

Fig. 16 Dissipated power $V s$ crank angle

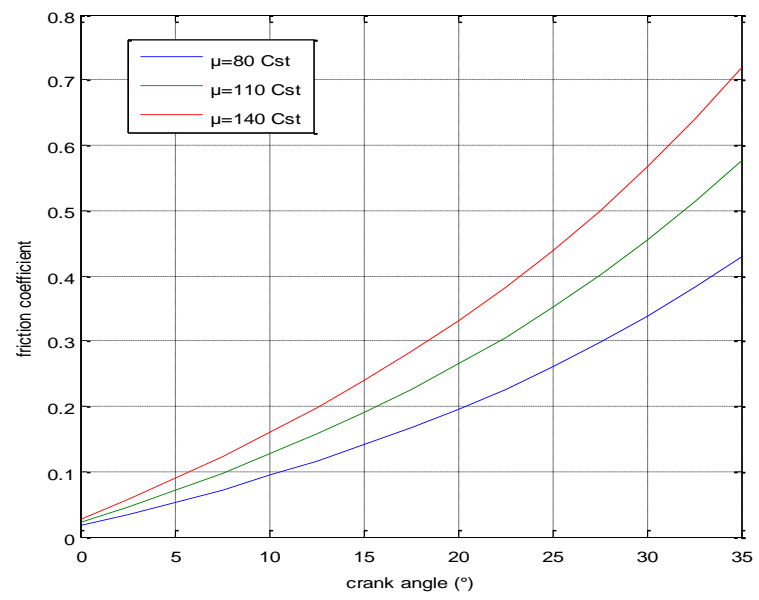

Fig. 17 Coefficient of friction $V s$ crank angle

6.3. Effect of the load $W$ for $\delta($ delta $)=0.2, \mu=80 \mathrm{cst}$

Fig. 18 gives the hydrodynamic pressure between the ring and the cylinder. This pressure is maximum at the point $\mathrm{C}$ due to the influence of the profile of the ring and of the combustion gases on the oil film; the hydrodynamic pressure is proportional to the load $W$.

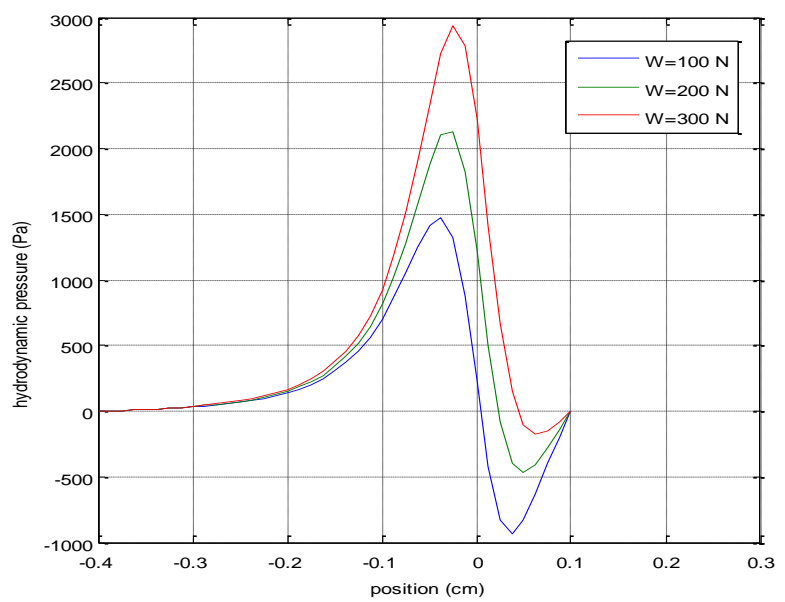

Fig. 18 Comparison of the results of the hydrodynamic pressure with different load $W$

Figs. 19 and 20 represent the variation of the minimum film thickness of the oil film and the force of fric- 
tion. The force of friction is inversely proportional to the viscosity of the oil film and a function of time. Just for $W=100 \mathrm{~N}$ is a slight growth path minimum film thickness.

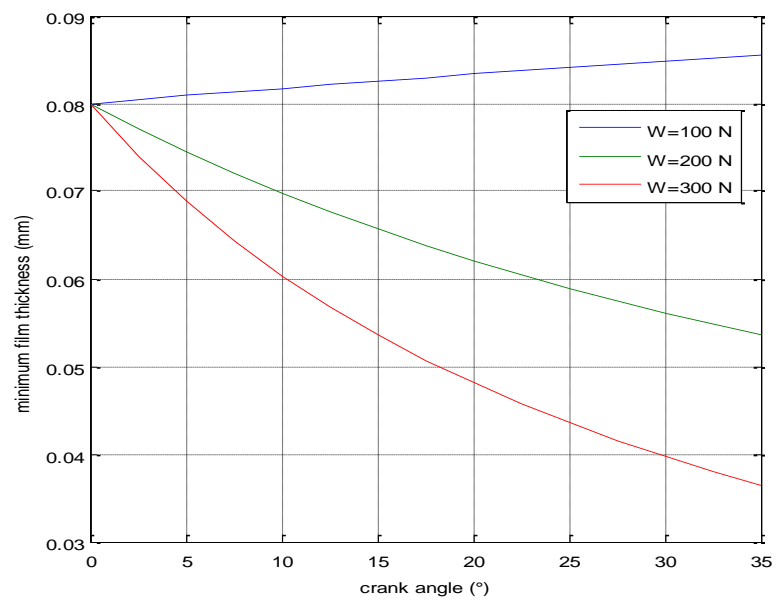

Fig. 19 Minimum film thickness $V s$ crank angle

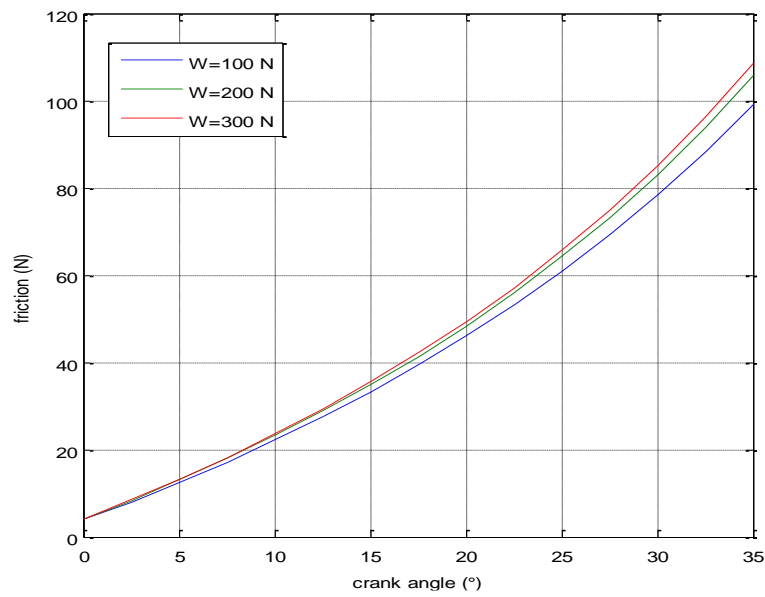

Fig. 20 Friction force $V s$ crank angle

Figs. 21 and 22 shows the variation of dissipated power and the friction coefficient. The two parameters are proportional to the crank angle and inversely proportional to the applied load $W$.

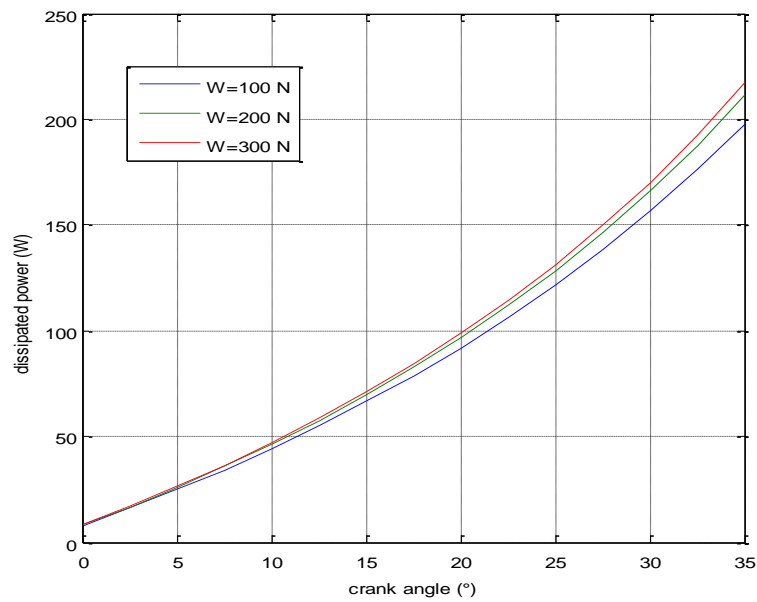

Fig. 21 Dissipated power $V s$ crank

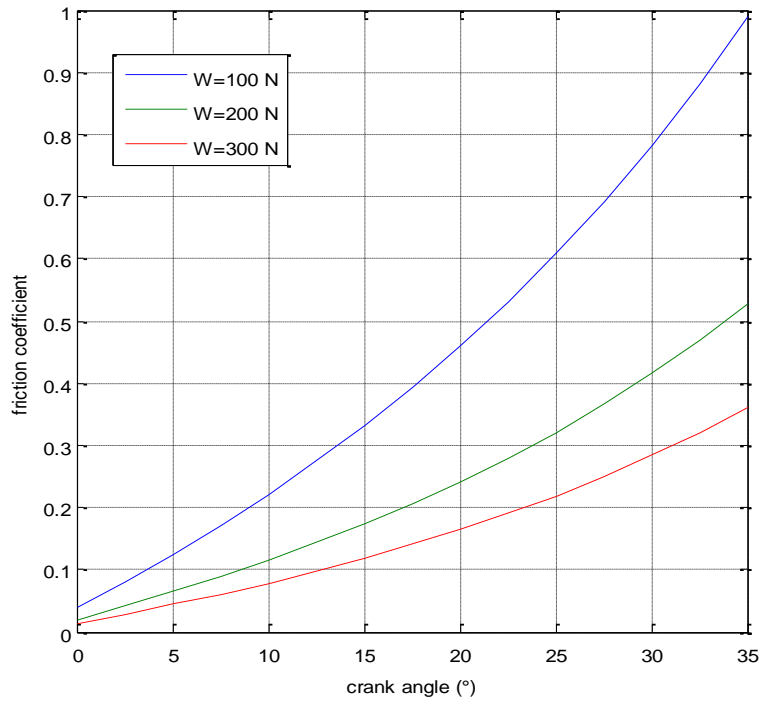

Fig. 22 Friction coefficient $V s$ crank angle

\section{Conclusion}

The results of tribological characteristics such as the movement of the piston, hydrodynamic pressure the minimum film thickness, the friction force, dissipated power and the coefficient of friction were studied in relation to the viscosity lubricant, ring profile and load $w$. Oil viscosity directly affects friction in the hydrodynamic regime. Indeed, the hydrodynamic friction increases with viscosity. The viscosity also indirectly affects the contact friction by determining the oil film thickness. The reduction in viscosity can reduce the hydrodynamic friction, but also leads to a reduction in the oil film thickness. The variation of oil film thickness depends on the pressure profile of the ring, geometric profile of the ring. The load $w$ of the piston is inversely proportional to the minimum film thickness of the oil hydrodynamic pressure and proportional to the friction force, the Lubricant viscosity and the speed of piston are proportional to the minimum film thickness of the oil.

\section{References}

1. Ayad, A.; Haiahem, A. 2008. Réduction du frottement dans un contact segment racleur/chemise d'un moteur à combustion interne, Revue des Energies Renouvelables CISM'08 Oum El Bouaghi, 37-50.

2. Sonthalia, A.; Kumar, C.R. 2013. The effect of compression ring profile on the friction force in an internal combustion engine, Tribology in Industry 35(1): 74-83.

3. Husain, S.Q.; Singh, K.P. 2011. Calculation of lubricating oil fil thickness between Piston rings and cylinder Liner, First National conference on Advances in Mechanical Engineering (NCAME-2011), 20th-21st May 2011, UIET, Panjab University, Chandigarh.

4. Wang, W.; Hu, Y.; Wang, H.; Liu, Y. 2001. Numerical simulation of piston ring in the mixed lubrication, State Key Laboratory of Tribology, Tsinghua University, Beijing 100084, China.

5. Dagilis, V.; Vaitkus, L. 2009. Experimental investigations and analysis of compressor's friction losses, Mechanika 5(79): 28-35.

6. Shahmohamadi, H.; Rahmani, R.; Rahnejat, H.; 
Garner, C.P. 2013. CFD modelling of cavitation phenomenon in piston ring/cylinder liner conjunction, World Tribology Congress 2013, Torino, Italy.

7. Malik, A.M.; Usman, A.; Qasim, A.S.; Mufti, R. 2010. Modeling of piston top ring lubrication by considering cylinder out-of-roundness in initial engine start up, Proceedings of the World Congress on Engineering 2010 Vol II, London, U.K.

8. Barrat, J-L.; Cottin-Bizonne, C., Bocquet, L.; Charlaix E. 2003. Low-friction flows of liquid at nanopatterned interfaces, Nature Materials 2: 237-240.

9. Bhatt, DV.; Bulsara, M.A.; Mistry, K.N. 2009. Prediction of oil film thickness in piston ring - cylinder assembly in an i c engine, Proceedings of the World Congress on Engineering 2009 Vol II, London, U.K.

10. Kellaci, A.; Mazouzi, R.; Khelidj, B.; Bounif, A. 2010. The effect of lubricant rheology on piston skirt/cylinder contact for an internal combustion engine, Mechanika 1(81): 30-36.

11.Jeng, Y.R. 1992. Theoretical analysis of piston-ring lubrification part I-fully flooded lubrication, Tribology Transactions 35(4): 696-706. http://dx.doi.org/10.1080/10402009208982174.

12. Mishra, P.C. 2014. A review of piston compression ring tribology, Tribology in Industry 36(3): 269-280.

13. Venkatesh, S. 1975. Analysis of piston ring lubrication, Applied Scientific Research 31: 309-319. http://dx.doi.org/10.1007/BF00389221.
A. Soualmia, M. Bouchetara

\section{NUMERICAL MODELLING OF THE \\ HYDRODYNAMIC BEHAVIOUR OF THE COUPLE PISTON-LINER}

\section{S u m m a r y}

The hydrodynamic behaviour of piston ringcylinder liner is complex and it is difficult to predict its efficiency at the design stage. The piston ring has been the subject of many theoretical and experimental investigations from many viewpoints. In all these investigations, a known profile is assumed for the piston ring face and the minimum oil film thickness, hdrodynamic pressure distribution is computed under a multitude of simplifying assumptions. This project aims to develop a numerical model of piston ring dynamics and lubrication in internal combustion engines, it is currently estimated that the piston ring cylinder bore friction accounts for up to $25 \%$ of the power loss in a typical engine, while oil transported to the combustion chamber by the piston and ring-pack contributes significantly to engine emissions. A profile of piston ring model was first developed to allow fast calculation of approximate piston ring dynamics.

The finite difference is applied to solve the governing equations of lubrication of the piston rings and to calculate the hydrodynamic pressure. The ring is assumed to have a circular profile in the direction of motion. This profile changes with time because tilting of the ring with the engine cycle is taken into account.

Keywords: piston ring, piston ring profil, hydrodynamic lubrication, friction coefficient, oil viscosity.

Received May 04, 2014

Accepted September 17, 2015 